\title{
Snow White and the Seven Dwarfs: a fairytale for endocrinologists
}

\author{
Athanasios Zervas ${ }^{1}$, George Chrousos ${ }^{2,3}$ and Sarantis Livadas ${ }^{1}$ \\ ${ }^{1}$ Endocrine Unit, Athens Medical Centre, Athens, Greece \\ ${ }^{2}$ Division of Endocrinology, Metabolism and Diabetes, First Department of Pediatrics, University Research Institute of Maternal and Child Health and \\ Precision Medicine, and UNESCO Chair on Adolescent Health Care, National and Kapodistrian University of Athens, Athens, Greece \\ ${ }^{3}$ National and Kapodistrian University of Athens Medical School, 'Aghia Sophia' Children's Hospital, Athens, Greece
}

\begin{abstract}
'Snow White and the Seven Dwarfs', a fairytale that is widely known across the Western Key Words world, was originally written by the Brothers Grimm, and published in 1812 as 'Snow White'. • growth Though each dwarf was first given an individual name in the 1912 Broadway play, in Walt Disney's 1937 film 'Snow White and the Seven Dwarfs', they were renamed, and the dwarfs have become household names. It is well known that myths, fables, and fairytales, though appearing to be merely children's tales about fictional magical beings and places, have, more often than not, originated from real facts. Therefore, the presence of the seven brothers with short stature in the story is, from an endocrinological point of view, highly intriguing, in fact, thrilling. The diversity of the phenotypes among the seven dwarfs is also stimulating, although puzzling. We undertook a differential diagnosis of their common underlying disorder based on the original Disney production's drawings and the unique characteristics of these little gentlemen, while we additionally evaluated several causes of short stature and, focusing on endocrine disorders that could lead to these clinical features among siblings, we have, we believe, been able to reveal the underlying disease depicted in this archetypal tale.

\section{Introduction}

The famous Brothers Grimm fairytale 'Snow White' has been, without a doubt, an enchanting narrative for every Western child during at least the past two centuries. Meanwhile, for the endocrinologist, the folktale portrayal of seven dwarf brothers, very possibly based on an early representation of certain facts, constitutes a difficult diagnostic challenge. The aim of this paper was to discover and as closely as possible attribute a distinctive clinical condition to each of the dwarf male members of the same family and to provide the reader with a scientific or clinical explanation of the diversity of phenotypes described by the Brothers Grimm and depicted in Walt Disney's 1937 film 'Snow White and the Seven Dwarfs'.

The art of the differential diagnosis is based on the combination of a detailed clinical examination and assembly of a patient's personal and family history, augmented by the physician's scientific knowledge and experience, which will guide them through appropriate laboratory testing to the correct diagnosis (1). However, as in this case, no laboratory tests can be available for evaluation, our diagnosis must be based on the clinical characteristics of the dwarfs, as they were set down by Disney's illustrators and shown on celluloid.

In the 1937 Broadway production recounting the story, the seven dwarfs were first given individual names (their names and personalities are not stated in the original fairytale); Walt Disney not only furnished them with different names but also elaborated upon their individual characteristics (2) (Figs 1 and 2). Judging from the attributes he gave them, it is very likely that Walt

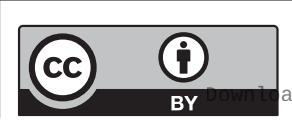

This work is licensed under a Creative Commons Attribution 4.0 International License. 
Disney's illustrators were familiar with a family of dwarfs, granted that their movie features are, indeed, typically encountered in subjects with dwarfism. The dwarfs' names were chosen from a pool of about 50 potential ones, with the final names adapted being Doc, Grumpy, Happy, Sleepy, Bashful, Sneezy, and Dopey. These names and the characteristics of each dwarf are listed in Table 1 (3). In our study, the original Disney film production drawings (4) were used in an attempt to determine the seven dwarfs' phenotypes, which was critical in pursuing our clinical investigation of these well-known characters.

\section{How short were our heroes?}

Any modern-day movie dealing with a crime or crimes typically shows the scene where the arrested individual has a 'mug shot' taken of him at the police station - via which we may also gain a rough idea of his height or stature. Definitely, in any enquiry into an individual's characteristics, height is of key importance. Thus, our first query concerns the actual stature of our heroes. The original production drawings (4) include the following specifics: 'Doc is about $1 / 4$ head taller than the other dwarfs', 'Grumpy is the average size of dwarfs', and 'Dopey is a little shorter than the [others]'. In the same drawings, we see horizontal lines showing the comparative sizes of the dwarfs and Snow White. Based on the latter, we estimated that the height ratio between Snow White and the dwarfs ranges from 1.77 (Doc) to 1.95 (Dopey). Grumpy was, thus, of average size among the dwarfs, with a ratio of 1.88.

Accordingly, the next question was: what was Snow White's height? Judging from the facial traits in the production drawings and from the story itself (e.g. Love's First Kiss given by the Prince), we may assume that Snow White was $15-17$ years old, that is, in mid-to-late adolescence. At this age, according to the Centers for Disease Control and Prevention (CDC) growth charts, the mean height of the American female ranges from 161.1 to $162.5 \mathrm{~cm}$ (5). Given that the mean female height has not changed substantially during the last 100 years (6) and assuming that Disney wanted a body composition familiar to the average filmgoer, we conclude that the abovementioned range may represent Snow White's actual height. Thus, the dwarfs' heights should range between 82.56 and $83.28 \mathrm{~cm}$ (Dopey) to between 90.61 and 91.40 $\mathrm{cm}$ (Doc), with the rest of the dwarfs distributed in between. Short stature (SS) is defined as a height below the third percentile or greater than two S.D. below the mean height for chronological age. Hence, if our hypothesis is correct, the dwarfs' height will certainly have been collectively below the fourth centile on the CDC growth chart (7). According to the current UK guidelines, this is a height compatible with the diagnosis of dwarfism, which considers evaluation for short stature after a single height measurement lower than the fourth centile at 5 years of age (the Coventry Consensus) (8).

\section{The unusual suspects}

The second query was what kind of dwarfism our little fellows suffered from. According to one of the currently used classifications, the causes of short stature are numerous (Table 2), and the list is constantly growing (9). Indeed, over the last three decades, extraordinary advances in our understanding of the genetic bases of growth abnormalities have taken place, with the identification of many monogenic causes of growth disorders. In addition, genome-wide association studies have revealed more than 600 variants associated with several human traits, explaining small fractions of phenotypic variations. It was determined that height is a classic polygenic trait that justifies approximately $80 \%$ of the variance $(10,11)$.

The initial step in the evaluation of a subject with short stature is to determine whether it is proportionate or disproportionate and whether any dysmorphic features exist. Proportionate short stature defines an unusually small person, whose body parts are appropriate for the

Table 1 Names and characteristics of the seven dwarfs.

\begin{tabular}{|c|c|}
\hline Name & Characteristics \\
\hline Doc & He is the leader of the seven dwarfs, wears glasses, and often mixes up his words. \\
\hline Bashful & Very shy and sweet. He is also described as cute. He also has a rosy, blushy face and a small shy smile. \\
\hline Grumpy & He has the biggest nose of the dwarfs and is frequently seen with one eye shut. \\
\hline Sneezy & $\begin{array}{l}\text { Sneezy's name is due to his extraordinarily powerful sneezes (caused by hay fever), which are seen blowing even } \\
\text { the heaviest of objects across a room. }\end{array}$ \\
\hline Sleepy & Sleepy is always tired and appears slothful in most situations. \\
\hline Happy & Happy is the joyous dwarf and is usually portrayed laughing. \\
\hline Dopey & Dopey is the only dwarf who does not have a beard. He is clumsy and mute. \\
\hline
\end{tabular}

(c) 2021 The authors Published by Bioscientifica Ltd

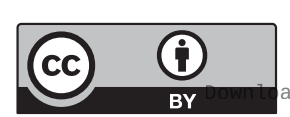

This work is licensed under a Creative Commons Attribution 4.0 International License. ded from Bioscientifica.com at 04/26/2023 11:46:55AM 


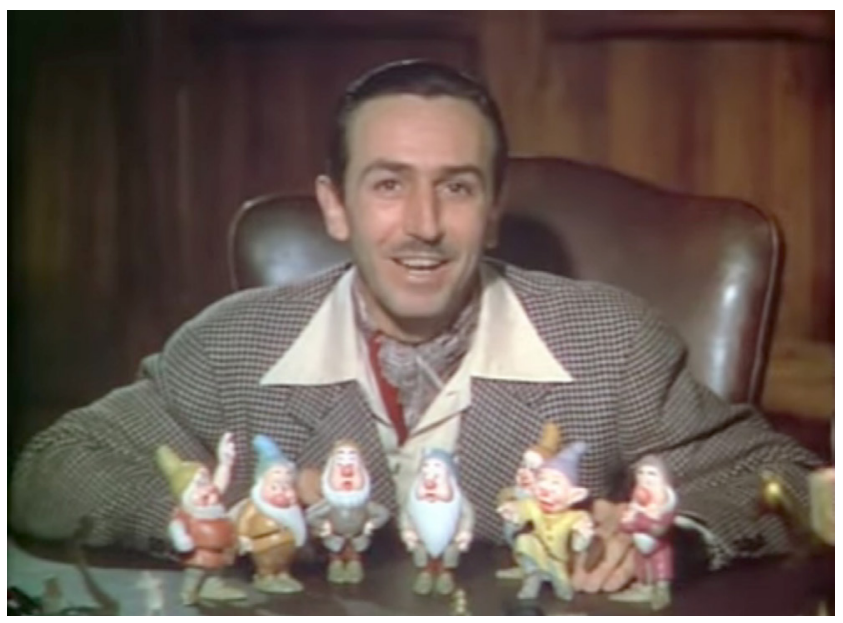

Figure 1

Walt Disney presenting the dwarfs' characteristics in the official theatrical trailer for Snow White and the Seven Dwarfs (1937). Walt Disney, Public domain, via Wikimedia Commons (https://commons.wikimedia.org/wiki/ File:Snow_White_and_the_Seven_Dwarfs_trailer_(1937).webm).

age, whereas in disproportionate short stature, the limbs are small compared with the trunk $(12,13)$. As seen in the drawings, none of the dwarfs exhibited disproportionality between trunk and limbs, which excludes congenital and acquired causes of disproportionate short stature. Therefore, disorders, such as the mucopolysaccharidoses, osteogenesis imperfecta, dyschondrosteoses, mucolipidoses, achondroplasia, hypochondroplasia, LeriWeiIl dyschondrosteosis, and hypophosphatemic rickets should be excluded.

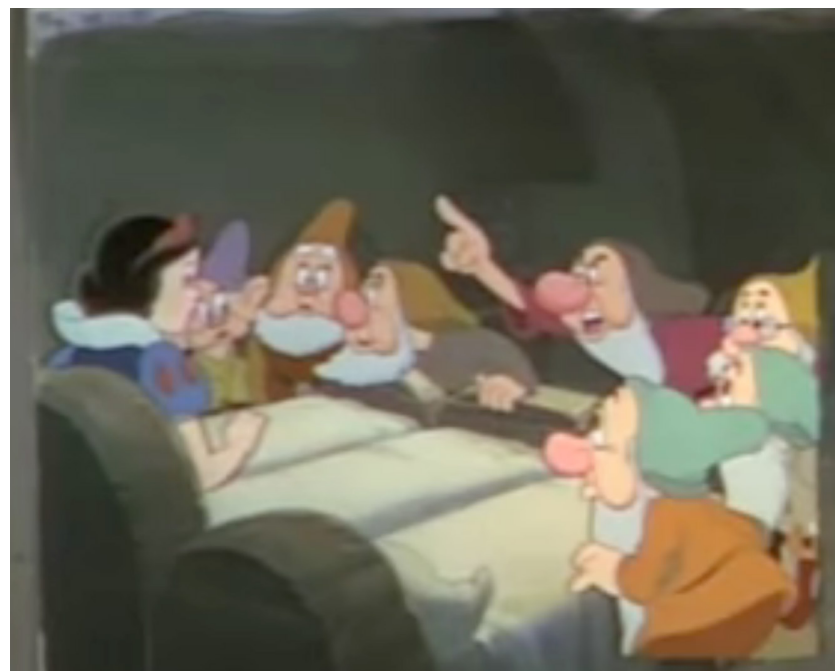

Figure 2

The dwarfs with Snow White in the official theatrical trailer for Snow White and the Seven Dwarfs (1937). Walt Disney, Public domain, via Wikimedia Commons (https://commons.wikimedia.org/wiki/File:Snow_White_and_ the_Seven_Dwarfs_trailer_(1937).webm).
Table 2 Classification of short stature.

ISS of known etiology

(A) Disproportionate

(1) Congenital: skeletal dysplasias

(2) Acquired: secondary to malformations, radiotherapy, tumors, and other diseases

(B) Proportionate of prenatal origin (newborn SGA)

Due to fetal factors

- Chromosomopathies (Turner, Down, Prader-Willi, etc.)

- Syndromic (Silver-Russell, Cornelia de Lange, Noonan, etc.)

- Primordial dwarfism (MOPD I, II, III)

Due to uterine of placental features

Due to maternal features

- Malnutrition

- Drugs

- Cardiac pathology

- Congenital infections (TORCH)

(C) Proportionate of postnatal origin

Malnutrition

Chronic infectious diseases

Organic diseases

- Gastrointestinal (celiac disease, Crohn's disease, cystic fibrosis, short intestine, etc.)

- Hepatic (biliary atresia, chronic hepatitis, liver transplantation, etc.)

- Renal (glomerular, interstitial, tubular)

- Cardiac (cianosant congenital cardiopathies)

- Pulmonary (asthma, bronchopulmonary dysplasia, obstructive apnea, etc.)

- Metabolic (poorly controlled diabetes mellitus)

- Hematological (chronic severe anemia, hemochromatosis)

- Oncological (leukemias, lymphomas, tumors of the CNS, etc.)

- CNS (idiopathic cerebral palsy, mental retardation, etc.)

- Rheumatological (chronic juvenile arthritis, systemic lupus erythematosus, etc.)

Endocrine diseases

- Growth hormone/IGF-1 deficiency or insensitivity

- Hypothyroidism

- Hypercortisolism

- Precocious puberty

- Pseudohypoparathyroidism

- Inherited rickets (hypocalcemic and hypophosphatemic)

- Diabetes mellitus with poor control

- Diabetes insipidus without treatment

Psychosocial

II SS of unknown etiology: ISS

Normal variants of SS

- FSS

- CDGP

- Association of FSS and CDGP

Other causes as yet unknown

CDGP, constitutional delay of growth and puberty; FSS, familial SS; ISS idiopathic SS, SS, short stature. 
With regard to the issue of dysmorphic features, there are a number of signs that lead to the diagnosis of several syndromes, for example, the existence of a short nose with anteverted nostrils (Smith-Lemli-Opitz), continuous eyebrows (Cornelia de Lange), the absence of adipose tissue (leprechaunism), or alopecia (progeria) (14). However, based on the production drawings and on the characters as seen in the movie, we observe no significant characteristics pointing to any of the various syndromes associated with dysmorphic features, such as chromosomopathies, and syndromic or primordial dwarfism.

We, thus, concluded that our heroes were suffering from some cause of proportionate short stature. The fact that the seven dwarfs were siblings is compatible with a similar underlying genetic defect. Whether this disorder was transmitted from their parents through a dominant or a recessive mode of inheritance cannot be, of course, ascertained. Therefore, congenital rather than acquired causes of growth hormone deficiency apply in this case (15). Similarly, it is also highly unlikely that the totality of seven dwarf siblings were all the product of intrauterine growth retardation accompanied by failure of catch-up (16).

Another element that may help us narrow down the large number of chronic conditions associated with short stature is the apparent physical abilities of the seven dwarfs. The fact that all of them were miners points to their ability to engage in strenuous physical activity. Consequently, clinical conditions associated with hypotonia or muscular atrophy as well as disorders in organ systems, such as the heart, liver, and lungs, could be eliminated (17). Furthermore, their clearly normal social life would not be compatible with psychosocial causes of short stature, while the fact that the majority of them were overweight or obese would rule out insufficient nutrient intake (18). Iatrogenic causes could, of course, also be ruled out as well as constitutional delay of growth and puberty granted that children with the latter condition reach normal adult height in line with their genetic potential (19).

\section{Description, information, and data}

In any emergency alert (amber or silver), together with a recent photo of the missing person, we are briefly informed about his most exceptional characteristics so that we may form a visual image of the individual. Doc is the leader, wears glasses, and often mixes up his words. Bashful has a rosy blushy face and a small shy smile. He is very shy and sweet. Grumpy has the biggest nose of the dwarfs and is frequently seen with one eye shut. Sneezy suffers from extraordinarily powerful sneezes, which are seen blowing even the heaviest of objects across a room. Sleepy is always tired and appears lethargic in most situations. Happy is the joyous dwarf and is usually portrayed laughing, while Dopey is mute, clumsy, and beardless (3). Analyzing the above, we see that Doc and Dopey represent the extremes of the spectrum of a specific clinical condition (Doc the tallest and smartest, Dopey the shortest...as well as 'dopey'). In other words, we are looking for a clinical condition which, in its full expression, substantially decreases growth and cognition, while in milder forms these two aspects are less affected. These characteristics are presented in Table 1.

By pooling the above information, we are able to zoom in on a range of clinical conditions that would pertain to the seven dwarfs. Thus, it seems that their intellectual ability ranged from normal to low (Doc to Dopey), while their emotional status varied from happiness to depression (Bashful, Grumpy, Happy). Most of them were obese and had chubby, round faces. Furthermore, Sneezy obviously suffered from allergies and concurrent respiratory infections and Sleepy probably from sleep apnea. Finally, Dopey's absence of beard is compatible with hypogonadism, therefore, he most probably exemplifies the most severe form of the disorder affecting all members of this family. We are, therefore, searching for a genetic disorder with variable phenotypes causing short stature, obesity, round facies, mental retardation, sleep apnea, and hypogonadism. All these plausible features are depicted in Fig 3.

\section{The usual suspects}

We will now focus on several endocrinopathies associated with the abovementioned clinical characteristics. Endocrine disorders compatible with these features are

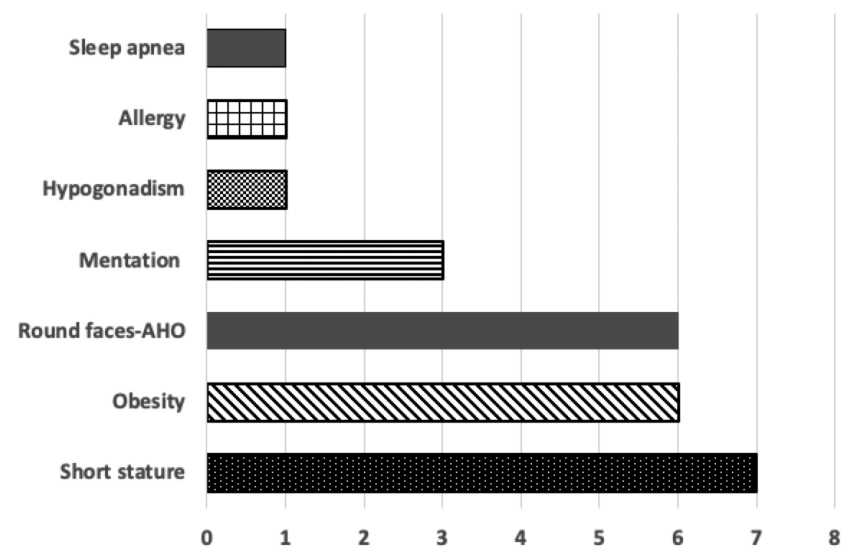

Figure 3

Plausible features depicted in Walt Disney's 1937 film Snow White and the Seven Dwarfs. 
hypothyroidism, Cushing syndrome, hypopituitarism/ GH deficiency, and pseudo-hypoparathyroidism. Although severe forms of congenital hypothyroidism should be ruled out due to the devastating neurodevelopmental consequences that it can bring about, we propose that the genetic basis of milder forms could be investigated (20). Thyroid dysgenesis usually occurs sporadically, with only $2-5 \%$ of cases being attributable to identifiable genetic mutations. The transcription factors PAX8, NKX2-1, and FOXE1 are all expressed in the developing thyroid and disruption of any of these genes can lead to failure of normal thyroid gland formation (21). Unlike thyroid dysgenesis, dyshormonogenesis is frequently due to a genetic defect in some element of thyroid hormone synthesis. Known genetic causes of dyshormonogenesis include mutations in thyroglobulin (TG), thyroperoxidase (TPO), dual oxidase 2 (DUOX2) and its accessory protein (DUOXA2), the sodiumiodide symporter (SLC5A5), pendrin (SLC26A4), and iodotyrosine deiodinase (22).

Central congenital hypothyroidism is caused by dysfunction of hypothalamic or pituitary control of the thyroid gland because of inadequate production or action of TSH. Specific defects in TRH or TSH signaling may result in isolated central congenital hypothyroidism. Until recently, the only known genetic causes of this condition were very rare mutations in the TRH receptor (TRHR) or the TSH $\beta$-subunit (TSHB) $(23,24)$. However, a 2012 study of 11 families with central congenital hypothyroidism discovered that loss-of-function mutations in the IGSF1 gene caused an X-linked syndrome of central hypothyroidism (25). Numerous cases of IGSF1 deficiency have since been described, making it the most common identifiable genetic cause of isolated central congenital hypothyroidism (26).

In addition to central hypothyroidism, further phenotypic findings include clinical and mild neurological phenotypes in affected males, such as hypotonia, delayed psychomotor development, clumsy behavior, and attention deficit disorder (27). The apparent lack of full clinical concordance of congenital hypothyroidism may be explained by a confluence of rare variants in several genes. The observed high rate of discordance for thyroid dysgenesis among monozygotic twins (who share nearly all variants in all genes) implies that a significant proportion of congenital hypothyroidism can most likely not be explained by germline genetic changes alone (28, 29). However, the assumed hypogonadism observed in Dopey and Doc's excellent cognitive abilities, Happy's constant good mood, and the dwarf brothers' ability to work in the mines cannot reasonably be explained against a background of congenital hypothyroidism.

The diagnosis of Cushing syndrome is intriguing. Endogenous Cushing syndrome is rare, with an incidence of 0.7-2.4 per million population per year. In childhood and adolescence, as in adults, exogenous glucocorticoid administration is the most common cause of Cushing syndrome, which definitely cannot not be the case in the Grimm Brothers' fairytale (30). In children, adrenocorticotropic hormone (ACTH) overproduction from a pituitary adenoma (Cushing disease) accounts for approximately $75 \%$ of all cases of Cushing syndrome in children over 7 years. In children under 7 years, adrenal causes of this disorder make up roughly 15\% of childhood Cushing syndrome, including bilateral hyperplasia, adenoma, or carcinoma. Ectopic ACTH and corticotropin-releasing hormone production is another rare cause of Cushing syndrome, accounting for less than $1 \%$ of cases in adolescents $(31,32)$. ACTH-producing pituitary adenomas are the most common cause of Cushing syndrome in childhood, and recently mutations in the ubiquitin-specific protease 8 (USP8) gene have been disclosed in a significant portion of corticotropinomas (33). Cushing disease is usually sporadic, though it may also be familial, and is known to occur in the context of MEN-1 and, rarely, due to mutations of the AIP gene (34). ACTH-secreting tumors have also been associated with mutations in cyclin E (CCNE), EGFR, CMPtk, and LAPTM4B in adults (defects that are, incidentally, rare in the pediatric Cushing disease population) (35). Primary pigmented nodular adrenocortical disease (PPNAD) is responsible for $2 \%$ of endogenous Cushing syndrome and is more frequent in females. The majority of cases are diagnosed post-pubertally, suggesting that growth is not affected in these patients. Furthermore, more than $90 \%$ of reported cases of PPNAD occur as one of the manifestations of Carney complex, which is accompanied by spotty skin pigmentation (lentigines, usually present around the lips, eyes, or genitalia) (36).

Establishing a diagnosis based on clinical features alone can be difficult. Some of the features that are thought to most reliably distinguish Cushing syndrome from simple obesity include proximal muscle weakness, easy bruising, and violaceous skin striae greater than $1 \mathrm{~cm}$ wide. Decreased linear growth along with progressive weight gain is one of the hallmarks of pediatric Cushing's syndrome, while decreased bone mineral density, osteoporosis, and fractures are present in $50-80 \%$ of patients (37). Bone loss can be more severe in primary adrenal disease compared to that due

This work is licensed under a Creative Commons Attribution 4.0 International License. ded from Bioscientifica.com at 04/26/2023 11:46:55AM 
to an ACTH-producing adenoma. This may be related to a protective effect of the higher adrenal androgen levels produced by increased ACTH stimulation. However, these findings have not been reproduced in many studies, and the significance of disease etiology in bone loss and fractures remains controversial (38). Psychiatric and cognitive deficits are present in 70-85\% of patients with Cushing syndrome. Depression, emotional lability, and irritability are the most common manifestations, while acute psychosis, mania, anxiety, panic attacks, suicidal ideation, and paranoia are infrequently encountered in this population (39). Hypercortisolemia is also associated with a decrease in brain volume, particularly of the hippocampus, and related impairment in learning along with short-term memory deficits (40). Excess glucocorticoids have a catabolic effect on skeletal muscles, skin, and connective tissue. Increased protein wasting and type II muscle-fiber atrophy are associated with significant muscle weakness, together with predominant involvement of the pelvic girdle musculature (41). Vertebral fractures, back pain, and depression lead to decreased mobility and disuse muscle atrophy. Persistent impairment of quality of life, primarily physical, and persistent muscle weakness have been documented even several years after remission (39). All things considered, some of the clinical features seem to apply to some of our 'subjects'. However, while obesity is obvious in all the dwarfs and irritability is manifest in Grumpy, hypomania in Happy, and learning impairment in Dopey, the rarity of familial occurrence of Cushing disease and, most importantly, the absence of muscle weakness and decreased mobility in the dwarfs make this diagnosis a less attractive candidate.

Regarding combined pituitary hormone deficiency (CPHD), also known as panhypopituitarism, this disorder is possibly detectable in several of the seven dwarfs' clinical manifestations. Indeed, it is probable that the illustrators of the movie version of the Grimm Brothers' fairytale might have seen or even studied individuals with CHPD, even though it is a rare disorder, with an estimated prevalence of 1 in 8000 individuals worldwide. The genetic basis for combined CPHD is complex, involving over 30 genes in a variety of syndromic and non-syndromic presentations. Recessive mutations within the pituitaryspecific transcription factor prophet of Pit1, or PROP1, are associated with CPHD (GH, prolactin (PRL), and TSH deficiency with additional LH and FSH deficiency). Mutations within POU1F1 are associated with GH, TSH, and PRL deficiencies, with TSH deficiency being highly variable (42).
Accumulating data concerning the genetic etiology of CPHD suggest that it is part of a spectrum disorder, with holoprosencephaly and septo-optic dysplasia at the severe end and hypogonadotropic hypogonadism ( $\mathrm{HH})$ and isolated GH deficiency (IGHD) at the mild end of the spectrum. CPHD and $\mathrm{HH}$ have overlapping genetic etiologies (43). In familial cases involving multiple affected individuals, the likelihood that the cause is genetic is increased, although environmental factors could play a role in the phenotypic diversity encountered in these families. Moreover, CPHD may prove to be a multifactorial disease as well, because identical mutations may produce a spectrum of phenotypic severity in different CPHD patients and incomplete penetrance is not uncommon in family pedigrees (44). Truncal adiposity (evident in all of our study dwarfs, except Dopey) is one of the most important clinical findings of GHD and GH resistance due to reduced lipolysis by GH-sensitive lipase. This condition may be a direct effect of the lack of GH as it is not reversed by IGF-I treatment in GH insensitivity syndrome (45).

$\mathrm{HH}$ is characterized by gonadotropin insufficiency, reduced sex steroid production, and delayed puberty or infertility. It can be caused by reduced production of GnRH due to failed migration of GnRH neurons during development as well as by impaired regulation of $\mathrm{GnRH}$ secretion. Mutations in many genes can cause $\mathrm{HH}$, and some of these genes are also implicated in CPHD (among them, CHD7, PROKR2, WDR11, FGFR1, and FGF8). In humans, a differentiating diagnosis between PROP1 and POU1F1 patients can be the presence or absence of gonadotropin deficiency, respectively, in addition to low GH, TSH, and PRL (46). In our 'study group', the candidate genes related to the phenotypic characteristics are PROP1 and SOX2, with PROP1 mutations being the most common genetic cause of CPHD. Patients with mutations in PROP1 are typically initially identified because of short stature due to GH deficiency. Most patients also exhibit reduced TSH (reflected in the various intellectual statuses of our dwarfs) and PRL at the time of diagnosis. At the onset of puberty, many patients with PROP1 mutations also exhibit LH and FSH deficiency and fail to develop secondary sexual characteristics (possibly applicable to Dopey). The loss of gonadotropins may also present as an evolving characteristic identified in adulthood. Although pituitary ACTH secretion should not be affected in patients carrying PROP1 mutations, several cases of secondary adrenal insufficiency have been reported, probably due to the loss of paracrine input from the other pituitary cells $(47,48)$.

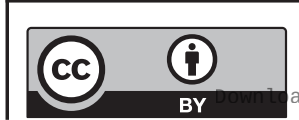

This work is licensed under a Creative Commons Attribution 4.0 International License. ded from Bioscientifica.com at 04/26/2023 11:46:55AM 
With regard to SOX2, the clinical features associated with SOX2 mutations include eye disorders (anophthalmia and microphthalmia), brain malformations (usually hippocampal), esophageal atresia, genital abnormalities, hypoplastic anterior pituitary and intellectual disabilities. Pituitary masses have been observed in affected patients, but they do not progress. The hypothalamic-pituitary phenotypes caused by variants in SOX2 include HH or CPHD (49). A combination of intellectual disabilities and HH could be reflected in Dopey's clinical phenotype. On the other hand, the other symptoms of the disease do not seem applicable to the seven dwarfs. Finally, a rare cause of familial short stature is gene variants, including IGF-1R heterozygous mutations or haploinsufficiency of the IGF-1 receptor gene. However, in these patients, clinodactyly, micrognathia, and a high-arched palate are observed, accompanied by severe hypoglycemic episodes (50). These features are not compatible with our case.

\section{The verdict}

In 1942, 5 years after the creation of the movie on which our investigation is mostly based, the renowned American endocrinologist Fuller Albright introduced the term 'pseudohypoparathyroidism' (PHP) to describe subjects with PTH-resistant hypocalcemia and hyperphosphatemia accompanied by a constellation of developmental and skeletal defects termed 'Albright hereditary osteodystrophy' (AHO). These features included short stature, round facies, brachydactyly (shortening of III, IV, and $\mathrm{V}$ metacarpals and I distal phalanx), obesity, and softtissue calcifications (51). Further research revealed that PHP encompasses a heterogeneous group of endocrine disorders, namely, PHP type 1A (PHP1A), PHP type 1B (PHP1B), PHP type 1c (PHP1C), and PHP type 2 (PHP2), all characterized by normal renal function and PTH resistance as well as variable resistance to other hormones. In contrast, presence of AHO features without evidence of resistance to hormone action is designated by the term 'pseudo-pseudohypoparathyroidism' (PPHP) (52).

In light of the above, our working hypothesis is, thus, that our heroes suffered from PHP and, based on the features presented (4), we will attempt to provide corroboration of our hypothesis. First of all, regarding short stature, the vast majority (50-80\%) of patients with PHP1A develop GHRH resistance, which subsequently leads to $\mathrm{GH}$ deficiency. Growth is, therefore, considerably affected and, during the prepubertal period, mild growth impairment is observed, followed by a blunted growth spurt and premature cessation of growth, resulting in short stature. Furthermore, defects in growth plates significantly contribute to the diminutive final height, as observed in all the little guys (53). Meanwhile, a big nose and round face are observed in $85 \%$ of the original Disney production drawings of the dwarfs, these characteristics being compatible with $\mathrm{AHO}$, even in the absence of brachydactyly, which is a fairly common sign of AHO. However, absence of the latter feature may simply be attributable to Disney's desire to depict the seven dwarfs with a more 'normal' appearance.

As it concerns obesity, which is evident in six of the seven 'subjects', that is, excepting Dopey, it is of note that children with PHP1A show decreased resting energy expenditure accompanied by hyperphagic symptoms (54). However, during adolescence and early adulthood, energy expenditure is enhanced, whereas hyperphagia declines and, consequently, obesity is less pronounced in adulthood than in childhood (55). Although sleep apnea is a wellknown complication of obesity, the observation that sleep disturbances are more often encountered (4.4-fold higher risk) in patients with PHP1A than in control subjects with comparable BMI is particularly intriguing $(56,57)$. This highly unusual feature exactly tallies with Sleepy's behavior.

Since three dwarfs (Bashful, Dopey, and Grumpy) suffered from mild-to-moderate cognitive dysfunction (Fig 3), this strongly indicates the diagnosis of PHP1A, given that mentation is impaired in approximately half of these patients and, moreover, subjects who have developed intracranial calcifications may experience seizures related to chronic neuropathic changes (58). With regard to Sneezy's extraordinary bouts of sneezing, it is of interest that increased prevalence of asthma and allergies are observed in patients with PHP1A (59). Finally, these patients may be hyporesponsive to the biologic effects of other peptide hormones that use Gs $\alpha$ to enhance cAMP production (60). Hypogonadism due to resistance to the action of gonadotropins is highly variable and has been poorly investigated, although it appears to be a compatible diagnosis with the absence of beard, as seen in Dopey. With regards to our specific investigation, given the fact that PHP is associated with skeletal deformities, one would wonder how the seven dwarfs managed to execute the backbreaking work in the mine without suffering any fractures. However, there are several studies indicating that the bone remodeling response to PTH is unharmed in PHP, leading to what would have been normal bone metabolism and bone mineral density in these 'subjects', which would allow them to carry out this grueling work $(61,62)$.

One may logically ask why we arrived at the verdict that PHP1a must be the correct diagnosis given such a great variety of different clinical findings in the seven dwarfs.

This work is licensed under a Creative Commons Attribution 4.0 International License. ed from Bioscientifica.com at 04/26/2023 11:46:55AM 
The fact is that our present-day expanding knowledge of the role of epigenetics in almost any function of the developing organism has hugely contributed to the understanding of this disorder and, thus, aided us in what we feel is the firm establishment of a diagnosis. The term 'epigenetics' denotes any modification of gene expression which cannot be attributed to changes in DNA sequence. PHP per se constitutes an epigenetic disease, since it is inherited in an autosomal dominant manner and, interestingly, the complete form (multihormone resistance with $\mathrm{AHO}$ ) is observed only upon maternal inheritance of stimulatory G protein (Gs $\alpha$ ) mutations, while patients inheriting the disease from the father suffer from PPHP $(63,64)$. Although PPHP cannot be excluded from the differential diagnosis, the lack of laboratory tests from our patients does not provide the needed material for a solid diagnosis of the above mentioned condition. However, one point against PPHP diagnosis is obesity is less prominent or absent among subjects with PPHP.

PHP1A is a result of loss of maternal expression of the GNAS gene that encodes the subunit of the Gs $\alpha$ mediating the signal transduction of the PTH receptor, whereas PHP1B results from methylation defects of maternally derived GNAS differentially methylated regions. However, recent data on both clinical and molecular aspects of these complex disorders have challenged the notion that there is a clear distinction between the various GNAS-related diseases, showing that some of them (PHP1A, PHP2B, and PHP1C) share more clinical and molecular similarities than originally described. Indeed, similar GNAS molecular alterations may lead to a broad spectrum of diseases, from isolated PTH resistance to multihormone resistance associated with AHO $(65,66)$. In addition, the expression of GNAS haploinsufficiency is tissue-specific, strengthening the selective resistance to several hormones and the observed variation of symptom severity. Moreover, analysis of PHP patients has shown the existence of different degrees of methylation defects associated with PHP1B, this possibly pointing to the presence of epigenetic mosaicism in these patients (67). On top of that, not to be overlooked, are epigenetic modifications of other hormonal/cognitive systems during the early years of life, which may affect detrimentally adult behavior and function (68).

It is well established that naturally occurring variations in maternal care during the first years of life are associated with changes in brain activity and behavior that may persist throughout adulthood. These effects are reversed by crossfostering, demonstrating a causal link between maternal care and gene expression programming. Equally importantly, the epigenetic response to maternal care is coordinated in clusters across broad genomic areas and not only in single candidate gene promoters, this highlighting the complexity of the early factors that affect adulthood skills and abilities $(69,70)$.

\section{Conclusions}

Hypothyroidism and Cushing syndrome having been excluded from our differential diagnosis, we conclude that CHPD deficiency and pseudohypoparathyroidism are the strongest candidates for an accurate clinical diagnosis of the seven dwarfs, since these conditions may account for most of their clinical characteristics. Interestingly, it seems that Sneezy plays a key role in our final diagnosis, because although GH deficiency has not been correlated with frequent infections, patients with PHP are, in fact, at increased risk of infections $(71,72)$. In conclusion, PHP1A accords with all of the clinical characteristics presented by each of Disney's seven dwarfs, making it the most likely diagnosis. What is most interesting in the abovedescribed investigation, analysis, and resultant diagnosis is the fact that endocrine challenges may be discovered everywhere, even in a fairytale. Indeed, given that the science of medicine can frequently be seen through the prism of literary and artistic depiction of human nature, and granted that this is evident in every aspect of human civilization, an 'outside the box' approach to examining this truth is likely to uncover new pathways in the pursuit of knowledge as well as a deeper understanding of man's evolution and development.

\section{Declaration of interest}

The authors declare that there is no conflict of interest that could be perceived as prejudicing the impartiality of this review.

\section{Funding}

This work did not receive any specific grant from any funding agency in the public, commercial or not-for-profit sector.

\section{Acknowledgement}

The authors are indebted to Ms Scarlett Gingell for her excellent editorial work and valuable contribution to this paper.

\section{References}

1 Richardson WS, Glasziou P, Polashenski WA\& Wilson MC. A new arrival: evidence about differential diagnosis. ACP Journal Club 2000 133 A11-A12. (https://doi.org/10.1136/ebm.5.6.164) 
2 Slethaug GE. Adaptation Theory and Criticism: Postmodern Literature and Cinema in the USA. Bloomsbury Academic, 2014.

3 Wikipedia. Seven Dwarfs. (available at: https://en.wikipedia.org/wiki/ Seven_Dwarfs)

4 Living Lines Library [blog]. Snow White and the Seven Dwarfs (1937) - Model Sheets \& Production Drawings. (available at: http://livlily. blogspot.com/2010/11/snow-white-and-seven-dwarfs-1937.html)

5 Fryar CD, Gu Q, Ogden CL \& Flegal KM. Anthropometric reference data for children and adults: United States, 2011-2014. National Center for Health Statistics. Vital Health Statistiscs 201639 1-46.

6 A Hundred Years Ago [blog]. Average Height for Males and Females in 1912 and 2012. (available at: https://ahundredyearsago. com/2012/02/06/average-height-for-males-and-females-in-1912and-2012/)

7 National Center for Health Statistics, National Center for Chronic Disease Prevention and Health Promotion. 2 to 20 years: Boys Stature Weight-for-age percentiles. Atlanta, GA, USA: CDC, 2000. (available at: https://www.cdc.gov/growthcharts/data/set1clinical/ cj41c021.pdf)

8 Hall DMB. Growth monitoring. Archives of Disease in Childhood 2000 82 10-15. (https://doi.org/10.1136/adc.82.1.10)

9 Bonafe L, Cormier-Daire V, Hall C, Lachman R, Mortier G, Mundlos S, Nishimura G, Sangiorgi L, Savarirayan R, Sillence D, et al. Nosology and classification of genetic skeletal disorders: 2015 revision. American Journal of Medical Genetics: Part A 2015 167A 2869-2892. (https://doi.org/10.1002/ajmg.a.37365)

10 Yengo L, Sidorenko J, Kemper KE, Zheng Z, Wood AR, Weedon MN, Frayling TM, Hirschhorn J, Yang J, Visscher PM, et al. Metaanalysis of genome-wide association studies for height and body mass index in 700000 individuals of European ancestry. Human Molecular Genetics 201827 3641-3649. (https://doi.org/10.1093/ hmg/ddy271)

11 Marouli E, Graff M, Medina-Gomez C, Lo KS, Wood AR, Kjae TR, Fine RS , Lu Y, Schurmann C, Highland HM, et al. Rare and lowfrequency coding variants alter human adult height. Nature 2017 542 186-190. (https://doi.org/10.1038/nature21039)

12 Mehlman CT \& Ain MC. Evaluation of the child with short stature. Orthopedic Clinics of North America 201546 523-531. (https://doi. org/10.1016/j.ocl.2015.06.006)

13 Argente J \& Pérez-Jurado LA. Genetic causes of proportionate short stature. Best Practice and Research: Clinical Endocrinology and Metabolism 201832 499-522. (https://doi.org/10.1016/j. beem.2018.05.012)

14 Jones KL \& Adam MP. Evaluation and diagnosis of the dysmorphic infant. Clinics in Perinatology 201542 243-261, vii. (https://doi. org/10.1016/j.clp.2015.02.002)

15 Aguiar-Oliveira MH \& Bartke A. Growth hormone deficiency: health and longevity. Endocrine Reviews 201940 575-601. (https://doi. org/10.1210/er.2018-00216)

16 Saenger P, Czernichow P, Hughes I \& Reiter EO. Small for gestational age: short stature and beyond. Endocrine Reviews 200728 219-251. (https://doi.org/10.1210/er.2006-0039)

17 Maghnie M, Labarta JI, Koledova E \& Rohrer TR. Short stature diagnosis and referral. Frontiers in Endocrinology 20188374.

18 Rogol AD \& Hayden GF. Etiologies and early diagnosis of short stature and growth failure in children and adolescents. Journal of Pediatrics 2014164 (Supplement) S1.e6-S14.e6. (https://doi. org/10.1016/j.jpeds.2014.02.027)

19 Verkauskiene R, Petraitiene I \& Albertsson Wikland K. Puberty in children born small for gestational age. Hormone Research in Paediatrics 201380 69-77. (https://doi.org/10.1159/000353759)

20 Prezioso G, Giannini C \& Chiarelli F. Effect of thyroid hormones on neurons and neurodevelopment. Hormone Research in Paediatrics 2018 90 73-81. (https://doi.org/10.1159/000492129)

21 Szinnai G. Clinical genetics of congenital hypothyroidism. Endocrine Development 201426 60-78. (https://doi.org/10.1159/000363156)
22 Peters C, van Trotsenburg ASP \& Schoenmakers N. DIAGNOSIS OF ENDOCRINE DISEASE: Congenital hypothyroidism: update and perspectives. European Journal of Endocrinology 2018179 R297-R317. (https://doi.org/10.1530/EJE-18-0383)

23 Bonomi M, Busnelli M, Beck-Peccoz P, Costanzo D, Antonica F, Dolci C, Pilotta A, Buzi F \& Persani L. A family with complete resistance to thyrotropin-releasing hormone. New England Journal of Medicine 2009360 731-734. (https://doi.org/10.1056/ NEJMc0808557)

24 Nicholas AK, Jaleel S, Lyons G, Schoenmakers E, Dattani MT, Crowne E, Bernhard B, Kirk J, Roche EF, Chatterjee VK, et al. Molecular spectrum of TSH-beta subunit gene defects in central hypothyroidism in the UK and Ireland. Clinical Endocrinology 2017 86 410-418. (https://doi.org/10.1111/cen.13149)

25 Sun Y, Bak B, Schoenmakers N, van Trotsenburg AS, Oostdijk W, Voshol P, Cambridge E, White JK, le Tissier P, Gharavy SN, et al. Loss-of-function mutations in IGSF1 cause an X-linked syndrome ofcentral hypothyroidism and testicular enlargement. Nature Genetics 201244 1375-1381. (https://doi.org/10.1038/ng.2453)

26 Persani L \& Bonomi M. The multiple genetic causes of central hypothyroidism. Best Practice and Research: Clinical Endocrinology and Metabolism 201731 255-263. (https://doi.org/10.1016/j. beem.2017.04.003)

27 Tenenbaum-Rakover Y, Turgeon MO, London S, Hermanns P, Pohlenz J, Bernard DJ \& Bercovich D. Familial central hypothyroidism caused by a novel IGSF1 gene mutation. Thyroid 201626 1693-1700. (https://doi.org/10.1089/thy.2015.0672)

28 Perry R, Heinrichs C, Bourdoux P, Khoury K, Szöts F, Dussault JH, Vassart G \& Van Vliet G. Discordance of monozygotic twins for thyroid dysgenesis: implications for screening and for molecular pathophysiology. Journal of Clinical Endocrinology and Metabolism 200287 4072-4077. (https://doi.org/10.1210/jc.2001-011995)

29 Cherella CE \& Wassner AJ. Congenital hypothyroidism: insights into pathogenesis and treatment. International Journal of Pediatric Endocrinology 20172017 11. (https://doi.org/10.1186/s13633-017. 0051-0)

30 Sharma ST, Nieman LK \& Feelders RA. Cushing's syndrome: epidemiology and developments in disease management. Clinical Epidemiology 20157 281-293. (https://doi.org/10.2147/CLEP.S44336)

31 Lodish M. Cushing's syndrome in childhood: update on genetics, treatment, and outcomes. Current Opinion in Endocrinology, Diabetes, and Obesity 201522 48-54. (https://doi.org/10.1097/ MED.0000000000000127)

32 Magiakou MA, Mastorakos G, Oldfield EH, Gomez MT, Doppman JL, Cutler Jr GB, Nieman LK \& Chrousos GP. Cushing's syndrome in children and adolescents. Presentation, diagnosis, and therapy. New England Journal of Medicine 1994331 629-636. (https://doi. org/10.1056/NEJM199409083311002)

33 Reincke M, Sbiera S, Hayakawa A, Theodoropoulou M, Osswald A, Beuschlein F, Meitinger T, Mizuno-Yamasaki E, Kawaguchi K, Saeki Y, et al. Mutations in the deubiquitinase gene USP8 cause Cushing's disease. Nature Genetics 201547 31-38. (https://doi.org/10.1038/ ng.3166)

34 Guaraldi F, Storr HL, Ghizzoni L, Ghigo E \& Savage MO. Paediatric pituitary adenomas: a decade of change. Hormone Research in Paediatrics 201481 145-155. (https://doi.org/10.1159/000357673)

35 Hernández-Ramírez LC \& Stratakis CA. Genetics of Cushing's syndrome. Endocrinology and Metabolism Clinics of North America 2018 47 275-297. (https://doi.org/10.1016/j.ecl.2018.02.007)

36 Kamilaris CDC, Faucz FR, Voutetakis A \& Stratakis CA. Carney complex. Experimental and Clinical Endocrinology and Diabetes 2019 127 156-164. (https://doi.org/10.1055/a-0753-4943)

37 Tack LJ, Tatsi C, Stratakis CA \& Lodish MB. Effects of glucocorticoids on bone: what we can learn from pediatric endogenous Cushing's syndrome. Hormone and Metabolic Research 201648 764-770. (https://doi.org/10.1055/s-0042-117721) 
38 Trementino L, Appolloni G, Ceccoli L, Marcelli G, Concettoni C, Boscaro M \& Arnaldi G. Bone complications in patients with Cushing's syndrome: looking for clinical, biochemical, and genetic determinants. Osteoporosis International 201425 913-921. (https:// doi.org/10.1007/s00198-013-2520-5)

39 Feelders RA, Pulgar SJ, Kempel A \& Pereira AM. The burden of Cushing's disease: clinical and health-related quality of life aspects. European Journal of Endocrinology 2012167 311-326. (https://doi. org/10.1530/EJE-11-1095)

40 Wingenfeld K \& Wolf OT. Stress, memory, and the hippocampus. Frontiers of Neurology and Neuroscience 201434 109-120. (https://doi. org/10.1159/000356423)

41 Müller LM, Kienitz T, Deutschbein T, Riester A, Hahner S, Burger-Stritt S, Berr CM, Oßwald A, Braun L, Rubinstein G, et al. Glucocorticoid receptor polymorphisms influence muscle strength in Cushing's syndrome. Journal of Clinical Endocrinology and Metabolism 2020105 dgz052. (https://doi.org/10.1210/clinem/dgz052)

42 Fang Q, George AS, Brinkmeier ML, Mortensen AH, Gergics P, Cheung LY, Daly AZ, Ajmal A, Pérez Millán MI, Ozel AB, et al. Genetics of combined pituitary hormone deficiency: roadmap into the genome era. Endocrine Reviews 201637 636-675. (https://doi. org/10.1210/er.2016-1101)

43 Giordano M. Genetic causes of isolated and combined pituitary hormone deficiency. Best Practice and Research: Clinical Endocrinology and Metabolism 201630 679-691. (https://doi.org/10.1016/j. beem.2016.09.005)

44 Castinetti F, Reynaud R, Saveanu A, Jullien N, Quentien MH, Rochette C, Barlier A, Enjalbert A \& Brue T. MECHANISMS IN ENDOCRINOLOGY: An update in the genetic aetiologies of combined pituitary hormone deficiency. European Journal of Endocrinology 2016 174 R239-R247. (https://doi.org/10.1530/EJE-15-1095)

45 Laron Z, Ginsberg S, Lilos P, Arbiv M \& Vaisman N. Body composition in untreated adult patients with Laron syndrome (primary GH insensitivity). Clinical Endocrinology 200665 114-117. (https://doi.org/10.1111/j.1365-2265.2006.02558.x)

46 Stamou MI, Cox KH \& Crowley Jr WF. Discovering genes essential to the hypothalamic regulation of human reproduction using a human disease model: adjusting to life in the '-omics' era. Endocrine Reviews 201536 603-621. (https://doi.org/10.1210/er.2015-1045)

47 Correa FA, Nakaguma M, Madeira JLO, Nishi MY, Abrão MG, Jorge AAL, Carvalho LR, Arnhold IJP \& Mendonça BB. Combined pituitary hormone deficiency caused by PROP1 mutations: update 20 years post-discovery. Archives of Endocrinology and Metabolism 201963 167-174. (https://doi.org/10.20945/2359. 3997000000139)

48 Ziemnicka K, Budny B, Drobnik K, Baszko-Błaszyk D, Stajgis M, Katulska K, Waśko R, Wrotkowska E, Słomski R \& Ruchała M. Two coexisting heterozygous frameshift mutations in PROP1 are responsible for a different phenotype of combined pituitary hormone deficiency. Journal of Applied Genetics 201657 373-381. (https://doi.org/10.1007/s13353-015-0328-z)

49 Alatzoglou KS, Andoniadou CL, Kelberman D, Buchanan CR, Crolla J, Arriazu MC, Roubicek M, Moncet D, Martinez-Barbera JP \& Dattani MT. SOX2 haploinsufficiency is associated with slow progressing hypothalamo-pituitary tumours. Human Mutation 2011 32 1376-1380. (https://doi.org/10.1002/humu.21606)

50 Wit JM, Oostdijk W, Losekoot M, van Duyvenvoorde HA, Ruivenkamp CA \& Kant SG. MECHANISMS IN ENDOCRINOLOGY: Novel genetic causes of short stature. European Journal of Endocrinology 2016174 R145-R173. (https://doi.org/10.1530/EJE-15-0937)

51 Albright F, Burnett CH, Smith PH \& Parson W. Pseudohypoparathyroidism - an example of 'Seabright-Bantam syndrome': report of three cases. Endocrinology 194230 922-932.

52 Mantovani G. Clinical review: Pseudohypoparathyroidism: diagnosis and treatment. Journal of Clinical Endocrinology and Metabolism 2011 96 3020-3030. (https://doi.org/10.1210/jc.2011-1048)
53 Kinoshita K, Minagawa M, Anzai M, Sato Y, Kazukawa I, Shimohashi K, Ota S \& Kohno Y. Characteristic height growth pattern in patients with pseudohypoparathyroidism: comparison between type 1a and type 1b. Clinical Pediatric Endocrinology 200716 31-36. (https://doi.org/10.1297/cpe.16.31)

54 Roizen JD, Danzig J, Groleau V, McCormack S, Casella A, Harrington J, Sochett E, Tershakovec A, Zemel BS, Stallings VA, et al. Resting energy expenditure is decreased in pseudohypoparathyroidism type $1 \mathrm{~A}$. Journal of Clinical Endocrinology and Metabolism 2016101 880-888. (https://doi.org/10.1210/jc.2015-3895)

55 Perez KM, Curley KL, Slaughter JC \& Shoemaker AH. Glucose homeostasis and energy balance in children with pseudohypoparathyroidism. Journal of Clinical Endocrinology and Metabolism 2018103 4265-4274. (https://doi.org/10.1210/jc.201801067)

56 Landreth H, Malow BA \& Shoemaker AH. Increased prevalence of sleep apnea in children with pseudohypoparathyroidism type 1a. Hormone Research in Paediatrics 201584 1-5. (https://doi. org/10.1159/000381452)

57 Curley KL, Kahanda S, Perez KM, Malow BA \& Shoemaker AH. Obstructive sleep apnea and otolaryngologic manifestations in children with pseudohypoparathyroidism. Hormone Research in Paediatrics 201889 178-183. (https://doi.org/10.1159/000486715)

58 Shoemaker AH \& Jüppner H. Non classic features of pseudohypoparathyroidism type 1a. Current Opinion in Endocrinology, Diabetes and Obesity 201724 33-38.

59 Mantovani G, Bastepe M, Monk D, Sanctis L, Thiele S, Usardi A, Ahmed F, Bufo R, Choplin T, De Filippo G, et al. Diagnosis and management of pseudohypoparathyroidism and related disorders: First International Consensus Statement. Nature Reviews of Endocrinology 201814 476-500.

60 Linglart A, Levine MA \& Jüppner H. Pseudohypoparathyroidism. Endocrinology and Metabolism Clinics of North America 201847 865-888. (https://doi.org/10.1016/j.ecl.2018.07.011)

61 Long DN, Levine MA \& Germain-Lee EL. Bone mineral density in pseudo-hypoparathyroidism type 1a. Journal of Clinical Endocrinology and Metabolism 201095 4465-4475. (https://doi.org/10.1210/ jc.2010-0498)

62 Kanatani M, Sugimoto T, Kaji H, Ikeda K \& Chihara K. Skeletal responsiveness to parathyroid hormone in pseudohypoparathyroidism. European Journal of Endocrinology 2001 144 263-269. (https://doi.org/10.1530/eje.0.1440263)

63 de Sanctis L, Giachero F, Mantovani G, Weber G, Salerno M, Baroncelli GI, Elli MF, Matarazzo P, Wasniewska M, Mazzanti L, et al. Genetic and epigenetic alterations in the GNAS locus and clinical consequences in pseudo-hypoparathyroidism: Italian Common Healthcare Pathways Adoption. Italian Journal of Pediatrics 201642 101. (https://doi.org/10.1186/s13052-016-0310-3)

64 Elli FM, de Sanctis L, Bollati V, Tarantini L, Filopanti M, Barbieri AM, Peverelli E, Beck-Peccoz P, Spada A \& Mantovani G. Quantitative analysis of methylation defects and correlation with clinical characteristics in patients with pseudohypoparathyroidism type I and GNAS epigenetic alterations. Journal of Clinical Endocrinology and Metabolism 201499 E508-E517. (https://doi.org/10.1210/jc.20133086)

65 Perez-Nanclares G, Romanelli V, Mayo S, Garin I, Zazo Seco C, Fernandez-Rebollo E, Martínez F, Lapunzina P, de Nanclares GP \& Spanish PHP Group. Detection of hypomethylation syndrome among patients with epigenetic alterations at the GNAS locus. Journal of Clinical Endocrinology and Metabolism 201297 E1060-E1067. (https://doi.org/10.1210/jc.2012-1081)

66 Brix B, Werner R, Staedt P, Struve D, Hiort O \& Thiele S. Different pattern of epigenetic changes of the GNAS gene locus in patients with pseudohypoparathyroidism type Ic confirm the heterogeneity of underlying pathomechanisms in this subgroup of pseudohypoparathyroidism and the demand for a new classification of

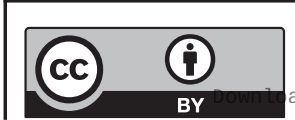

This work is licensed under a Creative Commons Attribution 4.0 International License. ded from Bioscientifica com at 04/26/2023 11:46:55AM 
GNAS-related disorders. Journal of Clinical Endocrinology and Metabolism 201499 E1564-E1570. (https://doi.org/10.1210/jc.2013-4477)

67 Lemos MC \& Thakker RV. GNAS mutations in

pseudohypoparathyroidism type $1 \mathrm{a}$ and related disorders. Human Mutation 201536 11-19. (https://doi.org/10.1002/humu.22696)

68 Kanherkar RR, Bhatia-Dey N \& Csoka AB. Epigenetics across the human lifespan. Frontiers in Cell and Developmental Biology 2014249. (https://doi.org/10.3389/fcell.2014.00049)

69 McGowan PO, Suderman M, Sasaki A, Huang TC, Hallett M, Meaney MJ \& Szyf M. Broad epigenetic signature of maternal care in the brain of adult rats. PLOS ONE 20116 e14739. (https://doi. org/10.1371/journal.pone.0014739)
70 Kuehner JN, Bruggeman EC, Wen Z \& Yao B. Epigenetic regulations in neuropsychiatric disorders. Frontiers in Genetics 201910268. (https://doi.org/10.3389/fgene.2019.00268)

71 Campos VC, Barrios MR, Salvatori R, de Almeida RP, de Melo EV, Nascimento AC, de Jesus AR \& Aguiar-Oliveira MH. Infectious diseases and immunological responses in adult subjects with lifetime untreated, congenital GH deficiency. Endocrine 201654 182-190. (https://doi.org/10.1007/s12020-016-1061-z)

72 Underbjerg L, Sikjaer T, Mosekilde L \& Rejnmark L.

Pseudohypoparathyroidism - epidemiology, mortality and risk of complications. Clinical Endocrinology 201684 904-911. (https://doi. org/10.1111/cen.12948)

Received in final form 22 February 2021

Accepted 16 April 2021

Accepted Manuscript published online 16 April 2021

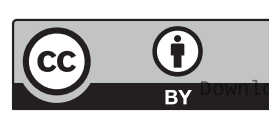

This work is licensed under a Creative Commons Attribution 4.0 International License.

ded from Bioscientifica.com at 04/26/2023 11:46:55AM 